\title{
Morphology and Morphometry of the Lingual Nerve in Relation to the Mandibular Third Molar
}

\author{
Isaac Kipyator Bokindo', Fawzia Butt ${ }^{2,3}$, Jameela Hassanali ${ }^{2}$ \\ ${ }^{1}$ School of Dental Sciences, University of Nairobi, Nairobi, Kenya \\ ${ }^{2}$ Department of Human Anatomy, University of Nairobi, Nairobi, Kenya \\ ${ }^{3}$ Department of Oral \& Maxillofacial Surgery, University of Nairobi, Nairobi, Kenya \\ Email: sillaisaac@gmail.com
}

Received 14 December 2014; accepted 28 December 2014; published 14 January 2015

Copyright (C) 2015 by authors and Scientific Research Publishing Inc.

This work is licensed under the Creative Commons Attribution International License (CC BY). http://creativecommons.org/licenses/by/4.0/

(c) (i) Open Access

\begin{abstract}
The position and branching of the lingual nerve (LN) in the mandibular third molar region were documented in 30 head hemi-sections (16: right and 14: left). In all the dissections, the LN was found below the level of the posterior alveolar crest (PAC). Branching was observed in 26 (86.7\%) of the 30 specimen in which one branch was most frequently given per hemi-section. All branches were located superior to the main trunk of the $L N$. The mean vertical distance of the $L N$ from the PAC was $10.3 \pm 5.2 \mathrm{~mm}$ (range: $2.8-19.9 \mathrm{~mm}$ ) whereas the mean antero-posterior distance was $7.1 \pm 2.8 \mathrm{~mm}$ (range: $1.3-15.6 \mathrm{~mm}$ ). The mean mandibular height from the PAC was $28.7 \pm 4.0 \mathrm{~mm}$ (range: $23.3-40.7 \mathrm{~mm}$ ). The vertical distance and mandibular height correlated positively giving a ratio of 1:2.7 between the two parameters. There was no significant difference between the two sides of the head. Position of the LN differed from previous studies suggesting that ethnicity may have a role in morphometry of the nerve. Use of different methodology may also contribute to this. Branches of the LN being closer to the PAC may be more prone to injury than the main trunk during surgical treatment.
\end{abstract}

\section{Keywords}

Lingual Nerve, Branches, Morphometry, Morphology

\section{Introduction}

Lingual nerve (LN) is a branch of the posterior trunk of the mandibular nerve given off in the infratemporal fossa, coursing close to the lingual aspect of the mandible at the region of the third molar. It carries general sensa- 
tion to the mucosa of the anterior tongue, mandibular lingual gingiva and the floor of the mouth and also receives the chorda tympani nerve that provides taste and parasympathetic innervation to the anterior two thirds of the tongue and the salivary glands [1].

Previous studies have shown inconsistent data on the position of the LN at the third molar region. Karakas et al. [2] reported a mean vertical distance of $9.51 \mathrm{~mm}$ which differed from a study by Miloro et al. [3] who found a mean of $2.75 \mathrm{~mm}$ in which using magnetic resonance imaging to visualize the nerve. Ethnicity may be a major factor leading to this difference since the data were obtained from different populations. A study on soft tissue facial profile by Oghenemavwe et al. [4] found that facial parameters of his study population differed with others. There are hardly any studies regarding metric data on the LN for the Kenyan population. Furthermore, even with the aid of data, the surgeon lacks useful parameters to help locate the nerve due to the wide ranges observed between studies.

Standard textbooks of anatomy do not mention the branching of the LN at the third molar region. Kim et al. [5] found branches to the lingual gingiva in $81.2 \%$ of their specimens. The course of these branches and their importance in third molar surgery has not been described. Such information may be useful to a surgeon so as to reduce the risk of severing these branches during surgery especially with use of lingual flap retractors [6].

LN damage may be related to the variant anatomy in the course of the nerve and use of different surgical techniques [7] resulting in significant morbidity to the patient [8] and potential medico-legal repercussion to the surgeon [9]. Data on the LN are especially useful to new practitioners since it has been shown that inexperience on the part of the practitioner is an important factor leading to LN injury [10]. True frequency of LN nerve injury remains controversial and current publications give the considerable variation of $0.2 \%$ to $22 \%$ [11]. Zuninga et al. [12] suggested that $75 \%$ of LN injuries were as a result of third molar removal with almost all involving osteotomies and tooth resections [13]. The use of lingual flap retraction has been implicated in nerve injury during third molar extraction [6] though Lata and Tiwari [14] reported that LN injury could occur without lingual flap retraction.

Data on the position and branching pattern of the LN in the African population are scarce. The study aimed to obtain morphometric data that may be used to locate the nerve and its branches so as to assist in surgical approach.

\section{Materials and Methods}

A total of 30 LN (16: right, 14: left) were studied from 30 head hemi-sections (HS) obtained from cadavers used during routine dissection at the Department of Human Anatomy, University of Nairobi. Only HS with intact third, second and first molars and free of pathologies such as tumors were included in the study. The lingual nerve (LN) was exposed by separating it from the mucosal covering using the blunt portion of scapel sequentially from the region it enters the tongue, advancing cranially up to the level of the lingula along the lingual plate. The most posterior point of the alveolar crest (PAC) was used to represent the most distal portion of the third molar and was used as the reference point of other measurements. Four points were identified on the specimen: $\mathrm{w}, \mathrm{x}, \mathrm{y}$ and $\mathrm{z} . \mathrm{x}$ represented the PAC, y represented the point on the lingual nerve vertical to PAC while $\mathrm{w}$ represented a point on the lingual nerve horizontal to PAC. $\mathrm{z}$ is the inferior most portion of mandible and vertical to PAC. With help of a pair of dividers, distances between the PAC and the LN in a vertical (xy) and anteroposterior (xw) axis were measured using a vernier caliper SOMET TM CN-25 1234 (accurate to $0.1 \mathrm{~mm}$ ). The height of the mandible from the PAC (xz) was also measured (Figure 1). Photographs were taken using a digital camera. Morphometric measurements were tabulated and analyzed using SPSS. Frequencies, means and standard deviations were calculated.

\section{Results}

The LN was present in all 30 HS. It emerged underneath the medial pterygoid muscle, coursing adjacent to the mandibular lingual mucosa, being closely applied to it. In all the specimens, the LN was located below the level of the PAC in the region of the third mandibular molar.

Of the $30 \mathrm{LN}, 26$ (86.7\%) gave branches which were located superior to the main LN trunk and the remaining 4 did not show branching. There were 19 (66.7\%) HSs with a single branch, 6 (20\%) had two branches and only $1(0.33 \%)$ had three branches (Figure 2). These branches were given next to the third molar, coursing on the lingual mucosa superior to the main LN trunk to supply the mucosa and the adjacent lower molars. In one HS with two branches, the lower branch followed the main trunk to the underside of the tongue (Figure 3(a) and Figure 3(b)). 


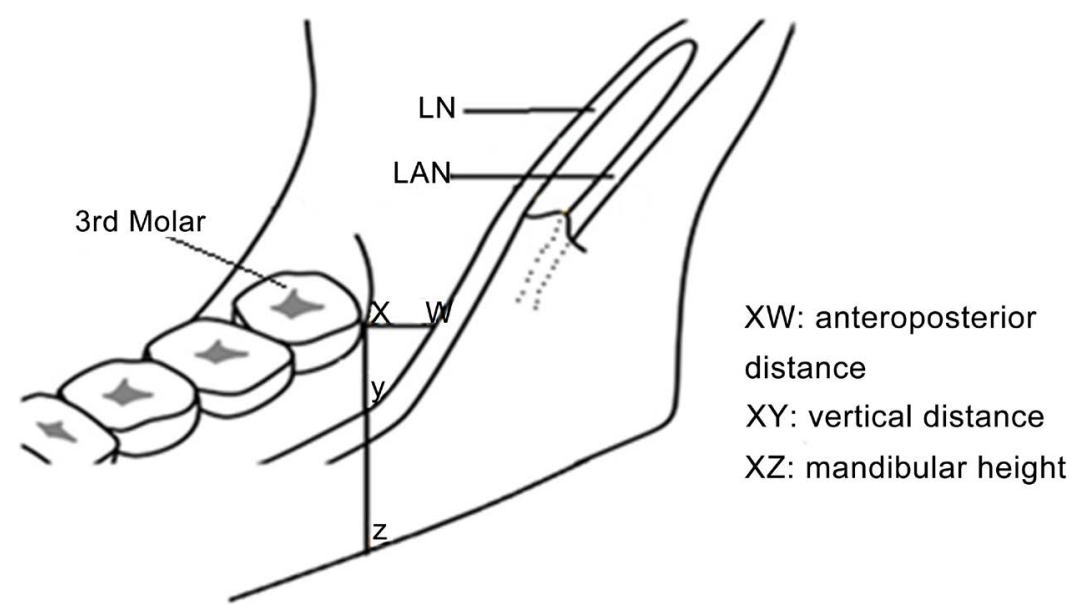

Figure 1. Diagram showing landmarks used in location of the lingual nerve LN.

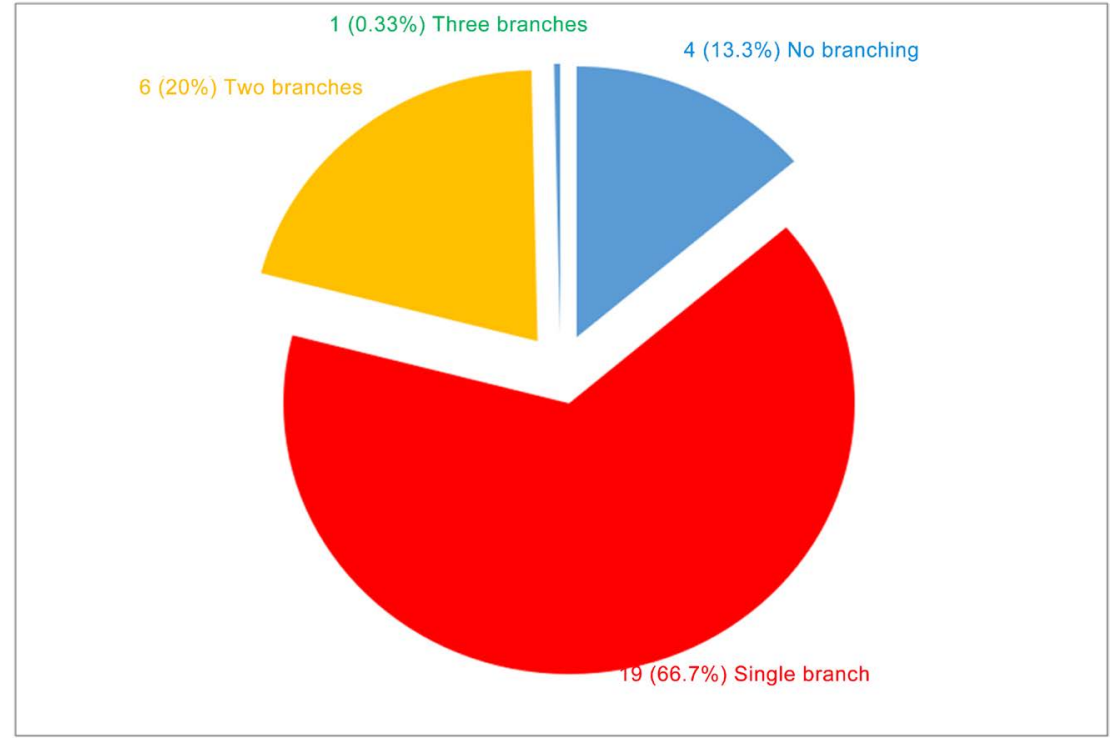

Figure 2. Pie chart showing the distribution of branches per HS.

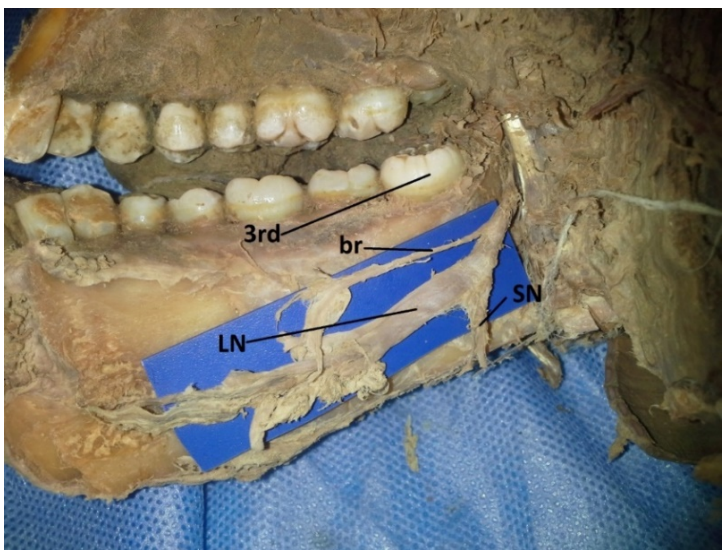

(a)

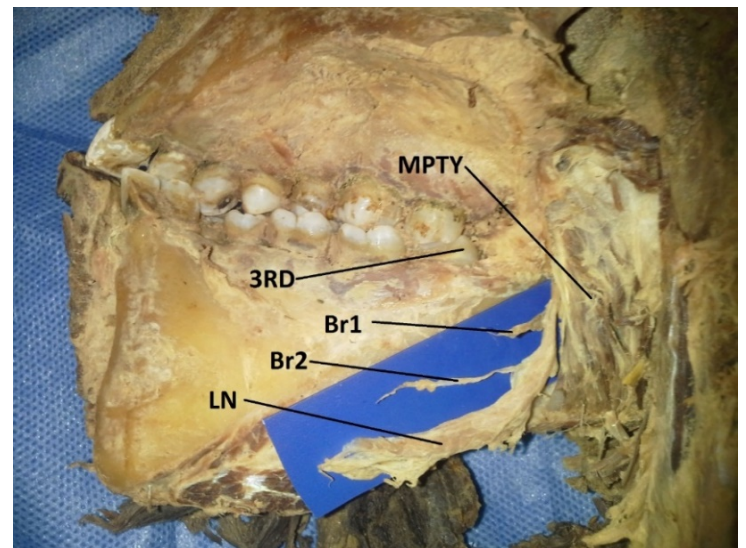

(b)

Figure 3. Photograph showing LN giving: (a) Single branch superior to the main trunk; (b) Two branches superior to the main trunk. 
The mean vertical distance of the LN from the PAC was $10.3 \pm 5.2 \mathrm{~mm}$ (range: 2.8 - $19.9 \mathrm{~mm}$ ) whereas the mean antero-posterior distance was $7.1 \pm 2.8 \mathrm{~mm}$ (range: 1.3 - $15.6 \mathrm{~mm}$ ). The mean mandibular height was 28.7 $\pm 4.0 \mathrm{~mm}$ (range: $23.3-40.7 \mathrm{~mm}$ ) (Table 1). The ratio between the mean vertical distance and the mandibular height was 1:2.7. The difference between the left and the right sides was found not to be statistically significant.

\section{Discussion}

In the present study, LN coursed below the alveolar crest in all the hemi-sections similar to Kim et al. [5]. In other studies, the LN coursed above the alveolar crest (Table 2). The observed differences may be due to the sample size although the study by Benninger et al. [15] and Behnia [16] show high incidence of crossing above the alveolar crest despite the marked difference in their samples. Racial and ethnic variability may also account for the differences [4]. Presence of the LN above the alveolar crest increases the risk of nerve injury during third molar extractions [17]. A buccal approach to third molar extraction is the method of choice in America which can be attributed to the variation in respect to the lingual crest [18].

There was a high incidence of branching (86.7\%) in the present study. This was similar to a study by Kim et al. [5] who found collateral twigs from LN in $81.2 \%$ of their specimens although they did not mention the location of the branches. We established the course of these branches superior to the main trunk of the LN which poses a risk of iatrogenic damage since they are much closer to the alveolar crest. Use of lingual flap retractors has been advocated to protect the LN [19] [20] as these retractors help improve access to the surgical site and simplify third molar removal. However, Pichler and Beirne [6] showed that use of the retractors increased the incidence of LN injury. These superior lingual branches may easily be severed with retraction of the LN.

The position of the LN below the lingual crest has been shown to vary between various populations. In this study the findings were similar to some studies but greatly differed with others (Table 3). Differences observed

Table 1. Means and standard deviations of vertical (xy), antero-posterior (xw) and height of mandible (xz).

\begin{tabular}{|c|c|c|c|c|c|c|c|c|c|}
\hline & \multicolumn{3}{|c|}{$\mathbf{x y}$} & \multicolumn{3}{|c|}{$\mathbf{x w}$} & \multicolumn{3}{|c|}{$\mathbf{x z}$} \\
\hline & $\mathrm{R}$ & L & $\mathrm{T}$ & $\mathrm{R}$ & L & $\mathrm{T}$ & $\mathrm{R}$ & $\mathrm{L}$ & $\mathrm{T}$ \\
\hline Mean (mm) & 10.5 & 11.1 & 10.3 & 7.5 & 6.8 & 7.1 & 28.1 & 29.4 & 28.7 \\
\hline SD (mm) & 4.8 & 5.9 & 5.2 & 3.2 & 2.3 & 2.8 & 2.9 & 4.94 & 4.0 \\
\hline Range (mm) & - & - & $2.8-19.9$ & - & - & $1.3-15.6$ & - & - & $23.3-40.7$ \\
\hline
\end{tabular}

$\mathrm{R}=$ right, $\mathrm{L}=$ left, $\mathrm{T}=$ total.

Table 2. Population differences in the incidence of LN above the alveolar crest.

\begin{tabular}{cccc}
\hline Country & Study & Sample size & Incidence of LN above the alveolar crest \\
\hline USA & Benninger et al., 2012 & 28 & $21 \%$ \\
German & Holze and Wolff, 2001 & 68 & $8.8 \%$ \\
Iran & Behnia, 2000 & 669 & $14.06 \%$ \\
South Korea & Kim et al., 2004 & 32 & $0.0 \%$ \\
Kenya & Present study & 30 & $0.0 \%$ \\
\hline
\end{tabular}

Table 3. A comparison of the mean vertical distances of the LN from various studies.

\begin{tabular}{cccr}
\hline Country & Study & Methodology & Mean vertical distance (mm) \\
Iran & Behnia et al., 2000 & Dissection & $3.01 \pm 0.42 \mathrm{~mm}$ \\
Turkey & Karakas et al., 2007 & MRI & $9.5 \pm 5.2 \mathrm{~mm}$ \\
USA & Miloro et al., 1997 & MRI & $2.75 \pm 0.97 \mathrm{~mm}$ \\
Turkey & Erdogmus et al., 2008 & Dissection & $7.06 \pm 1.3 \mathrm{~mm}$ \\
Kenya & Present study & Dissection & $10.3 \pm 5.2 \mathrm{~mm}$ \\
\hline
\end{tabular}


may be due to the methods applied although studies using similar methodology have also shown variable findings [7] [18]. The similarity of the data from studies by Karakas et al. [2] and Erdogmus et al. [7] which were from same population shows that probably ethnicity has a major influence on the LN dimensions. Previous studies have not correlated LN parameters with the mandibular height. The ratio of 1:2.7 established between the vertical distance of LN from PAC and height of mandible may provide guidelines to surgeons operating in this region in that the LN is located approximately one third down the mandible from PAC especially during osteotomies in orthognathic surgery. This can help the surgeon to relate the roots of the third molar with the suggested position of the nerve on the OPG. The antero-posterior measurements are important, especially where it pertains to distal bone removal during third molar extraction [17] and in inverted L osteotomies. Erdogmus et al. [7] obtained a mean distance of $9.3 \pm 2.1 \mathrm{~mm}$ which was larger than $7.1 \pm 2.8 \mathrm{~mm}$ in the present study. Mason [21] found considerable sensory loss following overhanging distal bone removal and this can be explained by the close proximity of the LN to the posterior aspect of the third molar. In the present study, LN courses below the alveolar crest unlike other findings from where it was above the crest. The high incidence of branching and proximity to the alveolar crest increases the risk of iatrogenic injury. Metric parameters may assist in location of the LN as per the OPG, approximately one third from the alveolar crest along the vertical height of the mandible.

Information on lingual nerve branching and position of the lingual nerve in relation to the third molar will enable surgeons operating around this area to plan properly for such procedures reducing risk of damage to the nerve preventing disability to the patient and possible medico legal repercussion.

\section{Conclusion}

Presence of branches of the lingual nerve and its closeness to alveolar crest increase the risk of iatrogenic injury. Metric data may assist in location on LN in relation to height of mandible as seen on OPG.

\section{Funding}

This work was supported by the department of Anatomy, University of Nairobi.

\section{Competing Interests}

There are no conflicts of interests.

\section{References}

[1] Berkovits, B.K., Holland, G.R. and Moxham, B.J. (2009) Oral Anatomy, Histology and Embryology. Mosby Elsevier, Edinburg, 86-88.

[2] Karakas, P., Uzel, M. and Koebke, J. (2007) The Relationship of the Lingual Nerve to the Third Molar Region Using Radiographic Imaging. British Journal of Dentistry, 203, 29-31.

[3] Miloro, M., Slone, W. and Chakeres, D. (1997) Assessment of the Lingual Nerve in the Third Molar Region Using Magnetic Resonance Imaging. Journal of Oral and Maxillofacial Surgery, 55, 474-480. http://dx.doi.org/10.1016/S0278-2391(97)90228-7

[4] Oghenemavwe, E.L., Osunwoke, A.E., Ordu, S.K. and Omovigho, O. (2010) Photometric Analysis of Soft Tissue Facial Profile of Adult Urhobos. Asian Journal of Medical Sciences, 2, 248-252.

[5] Kim, S., Hu, K., Chung, I., Lee, E. and Kim, H. (2004) Topographic Anatomy of the Lingual Nerve and Variation in the Communication Pattern of the Mandibular Nerve Branches. Surgery Radiologic Anatomy, 26, 128-163. http://dx.doi.org/10.1007/s00276-003-0179-x

[6] Pichler, J. and Beirne, O. (2001) Lingual Flap Retraction and Prevention of Lingual Nerve Damage Associated with Third Molar Surgery: A Systematic Review of Literature. Oral Surgery, Oral Medicine, Oral Pathology, Oral Radiology, and Endodontics, 91, 395-401. http://dx.doi.org/10.1067/moe.2001.114154

[7] Erdogmus, S., Govsa, F. and Celik, S. (2008) Anatomic Position of the Lingual Nerve in the Third Molar Region as Potential Risk Factors for Nerve Palsy. Journal of Craniofacial Surgery, 24, 264-270.

[8] Baqain, Z., Abukaray, A., Hassoneh, Y. and Sawair, F. (2010) Lingual Nerve Morbidity and Mandibular Third Molar Surgery: A Prospective Study. Karger Medical and Scientific Publishers, 19, $28-32$.

[9] Leggatt, D. (2002) The Legal Implications of Lingual Nerve Injuries. Annals of the Royal Australasian College of 
Dental Surgeons, 16, 115-122.

[10] Robert, R., Bacchetti, P. and Pogrel, A. (2005) Frequency of Trigeminal Nerve Injuries Following Third Molar Removal. Journal of Oral and Maxillofacial Surgery, 63, 732-735. http://dx.doi.org/10.1016/j.joms.2005.02.006

[11] Loescher, A., Smith, K. and Robinson, P. (2003) Nerve Damage and Third Molar Removal. Dental Update, 30, 375382.

[12] Zuninga, J., Gregg, J., Miloro, M. and Davis, L. (1998) The Accuracy of Clinical Neurosensory Testing for Nerve Injury Diagnosis. Journal of Oral and Maxillofacial Surgery, 56, 2-8. http://dx.doi.org/10.1016/S0278-2391(98)90904-1

[13] Queral-Godoy, E., Figueiredo, R., Valmaseda-Castellon, E., Berini-Aytés, L. and Gay-Escoda, C. (2006) Frequency and Evolution of Lingual Nerve Lesions Following Lower Third Molar Extraction. Journal of Oral and Maxillofacial Surgery, 64, 402-407. http://dx.doi.org/10.1016/j.joms.2005.11.010

[14] Lata, J. and Tiwari, A. (2011) Incidence of Lingual Nerve Paraesthesia Following Mandibular Third Molar Surgery. National Journal of Maxillofacial Surgery, 2, 137-140. http://dx.doi.org/10.4103/0975-5950.94467

[15] Benninger, B., Kloenne, J. and Horn, J. (2013) Clinical Anatomy of the Lingual Nerve and Identification with Ultrasonography. British Journal of Oral and Maxillofacial Surgery, 51, 541-544. http://dx.doi.org/10.1016/j.bjoms.2012.10.014

[16] Behnia, H., Kheradvar, A. and Shahrokhi, M. (2000) An Anatomic Study of the Lingual Nerve in the Third Molar Region. Journal of Oral and Maxillofacial Surgery, 58, 649-651. http://dx.doi.org/10.1016/S0278-2391(00)90159-9

[17] Lam, D.K. and Holmes, H.I. (2002) Lingual Nerve Damage during Removal of Mandibular Third Molars. Oral Health, 94, 13-26.

[18] Bernard, G. and Mintz, V. (2003) Evidence Based Means of Avoiding Lingual Nerve Injury Following Mandibular Third Molar Extractions. Medical and Health, 2, 179-182.

[19] To, E. and Chan, F. (1994) Lingual Nerve Retractor. British Journal of Oral and Maxillofacial Surgery, 32, $125-126$. http://dx.doi.org/10.1016/0266-4356(94)90145-7

[20] Pogrel, M. and Goldman, K. (2004) Lingual Flap Retraction for Third Molar Removal. Journal of Oral and Maxillofacial Surgery, 62, 1125-1130. http://dx.doi.org/10.1016/j.joms.2004.04.013

[21] Mason, D.A. (1998) Lingual Nerve Damage Following Third Molar Surgery. International Journal of Oral and Maxillofacial Surgery, 33, 33-38. 
Scientific Research Publishing (SCIRP) is one of the largest Open Access journal publishers. It is currently publishing more than 200 open access, online, peer-reviewed journals covering a wide range of academic disciplines. SCIRP serves the worldwide academic communities and contributes to the progress and application of science with its publication.

Other selected journals from SCIRP are listed as below. Submit your manuscript to us via either submit@scirp.org or Online Submission Portal.
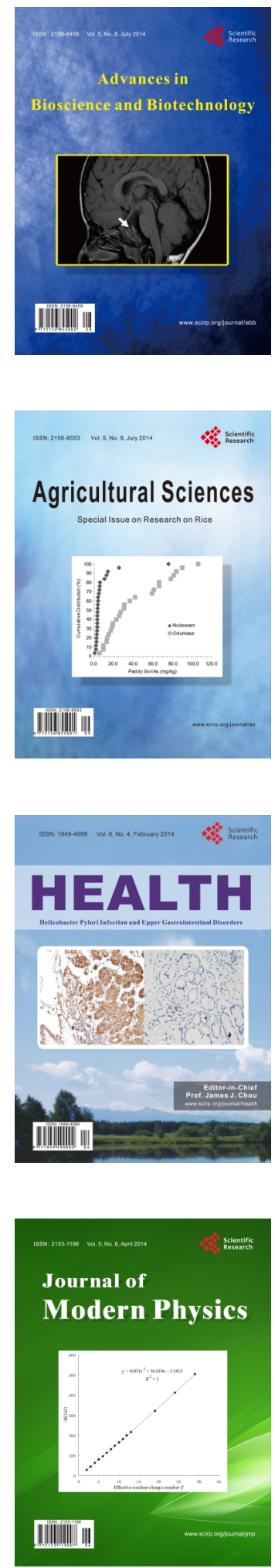
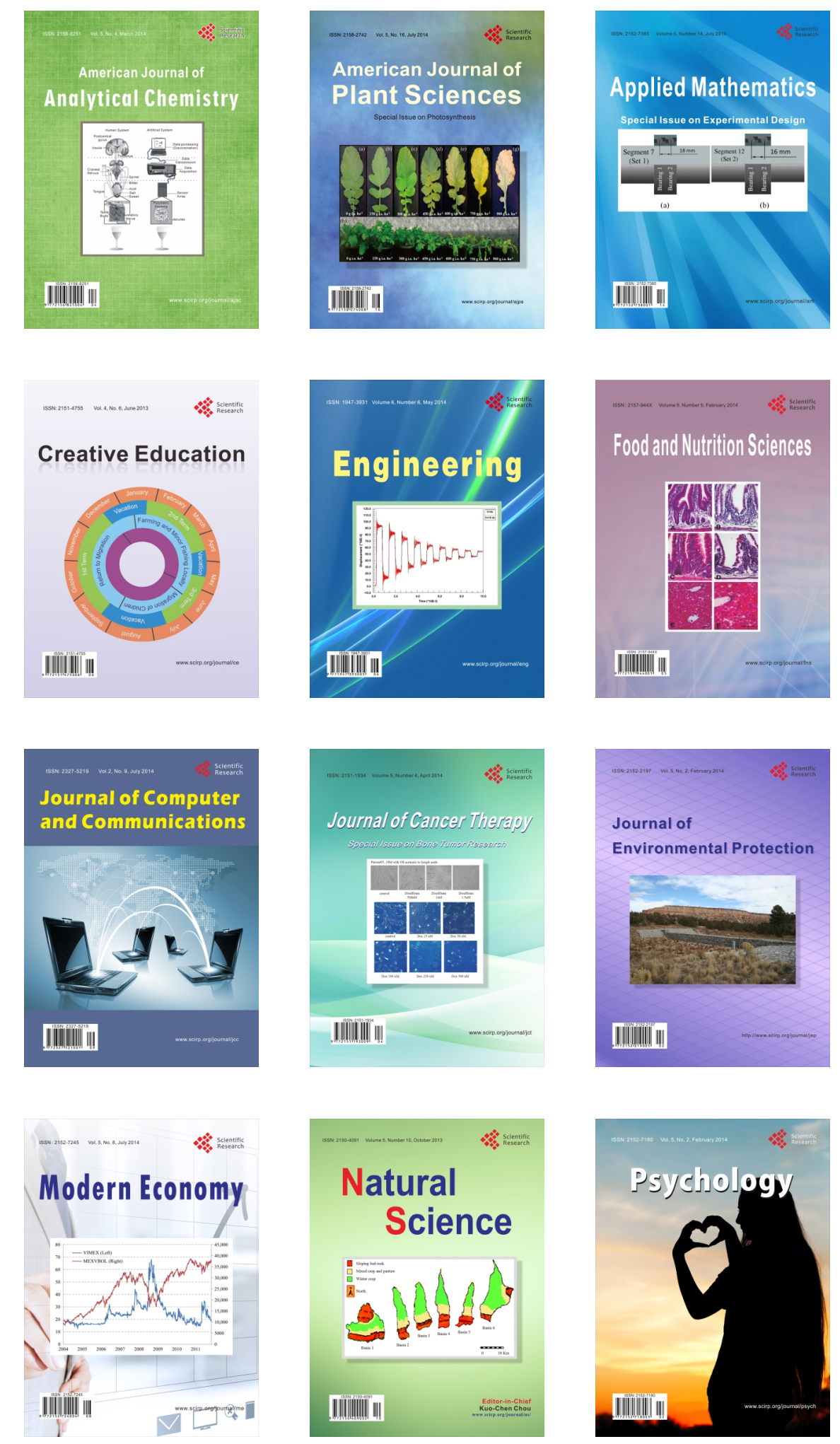